\title{
Catalytic Cracking of Ethanethiol over Various Solid Acid Catalysts*
}

\author{
by Masatoshi Sugioka** and Kazuo Aomura**
}

\begin{abstract}
Summary: Experimental studies were carried out to determine what kind of catalysts are effective for the cracking of ethanethiol using a pulse reactor.

Solid acid catalysts such as silica-alumina (SA), solid phosphoric acid (SPA), alumina $\left(\mathrm{Al}_{2} \mathrm{O}_{3}\right)$, hydrogen $\mathrm{Y}$ zeolite $(\mathrm{HY})$ and metal $\mathrm{Y}$ zeolite ( $\mathrm{MeY}$ ) showed a definite activity in the cracking of ethanethiol. However, solid bases such as $\mathrm{CaO}$ and $\mathrm{MgO}$ showed no activity.

From these results, it may be said that the solid acid catalysts accelerate the cracking o, ethanethiol. The cracking products of ethanethiol on SA, SPA, HY and MeY were only ethylene and hydrogen sulfide. In the case of ethanethiol cracking on $\mathrm{Al}_{2} \mathrm{O}_{3}$, the products were ethylene, hydrogen sulfide and a substantial amount of diethylsulfide which was formed by the disproportionation of ethanethiol.

Furthermore, detailed studies were made on the effective active sites of the solid acid catalysts which showed the activity in the cracking of ethanethiol. And it was concluded that the active sites of SA, SPA and HY were the Brönsted acid sites, and that the active sites of $\mathrm{Al}_{2} \mathrm{O}_{3}$ were both Lewis acid sites and basic sites, and that the active sites of $\mathrm{MeY}$ were mainly the metal ions.

In light of the nature of the active sites, reaction mechanisms were proposed for the cracking of ethanethiol over individual solid acid catalysts.
\end{abstract}

\section{Introduction}

The catalytic hydrocracking of organic sulfur compounds such as thiophenes has been widely studied as a model reaction of hydrodesulfurization of heavy oil ${ }^{1) ~ 5)}$. However, the catalytic cracking of organic sulfur compounds such as aliphatic thiols and aliphatic sulfides without hydrogen has scarecely been investigated. Thus, these are many points which remain uncertain regarding the active sites of the solid catalysts together with the reaction mechanism in the catalytic cracking of aliphatic thiols and aliphatic sulfides.

Furthermore, the molecular structure of thiol is quite similar to that of alcohol. However, no detailed studies have been made on the cracking of thiol over solid acid catalysts, which show high activity in the dehydration of alcohol. Thus, the studies of catalytic cracking of thiols over solid acid catalysts is of interest in connection with the dehydration of alcohol.

In the present study, as an organic sulfur compound, we selected ethanethiol from aliphatic thiol family and attempt was made to determine

* Received September 30, 1974.

** Laboratory of Analytical Chemistry, Faculty of Engineering, Hokkaido University (North 13, West 8, Sapporo 060) what kind of solid catalysts were effective for the cracking of ethanethiol.

It was observed that the solid acid catalysts showed the high activity in the cracking of ethanethiol as well as the dehydration of alcohol. And, we studied the effective active sites of the solid acid catalysts for the cracking and the reaction mechanisms of the cracking of ethanethiol on the solid acid catalysts.

\section{Experiment}

\subsection{Experimental Apparatus}

A conventional pulse reactor connected to a gaschromatograph was used with 5-m of tricresylphosphate as an analytical column. Helium, after drying on a molecular sieve, was employed as the carrier gas.

The reactor was a $U$ type pyrex glass tube of 4-mm ID, which was heated with an electric furnace. The temperature of the catalyst bed was controlled within $\pm 1^{\circ} \mathrm{C}$.

\subsection{Catalyst}

A commercially available $\mathrm{SA}, \mathrm{CaO}, \mathrm{MgO}$, kieselguhr $(\mathrm{KG})$ and $\mathrm{SiO}_{2}$ were used for the experiment. KG was treated with diluted hydrochloric acid. SPA was prepared by the method described in the previous paper $\left.{ }^{6}\right) . \mathrm{Al}_{2} \mathrm{O}_{3}$ was prepared by the hydrolysis of aluminum isopropoxide. MeY was prepared by ion exchange $\mathrm{NaY}$

Volume 17, No. 1, April 1975 
(SK-40) with aqueous solution of the respective cations. HY was prepared by ion exchange $\mathrm{NaY}$ with $\mathrm{NH}_{4} \mathrm{Cl}$ solution and was calcined. The percentage of ion exchange was determined by measuring the concentration of $\mathrm{Na}$ ion which was extracted into the solution after ion-exchange. An atomic adsorption spectrophotometer was used for the measurement of ion-exchange. The results are shown in Table 3. All catalysts were calcined in the air at $500^{\circ} \mathrm{G}$ for $3 \sim 4$ hours and were stored in a desicator.

Even with this treatment, the catalysts adsorbed a certain amount of water from the air. Prior to the experiment, thus, the catalysts were dried in a reactor tube at $450^{\circ} \mathrm{C}$ under a helium stream for about 30 minutes.

\subsection{Materials}

Highly pure ethanethiol, pyridine and cumene were used in the experiment without further purification. Gaschromatographic analysis indicated that the only trace amounts of impurities were contained in these substances.

\section{Results and Discussion}

\subsection{Catalytic Activities of Various Solid Catalysts for the Cracking of Ethanethiol}

The catalytic activities of various solid catalysts for the cracking of ethanethiol were examined at $400^{\circ} \mathrm{C}$ by passing the carrier gas at a flow rate of $30 \mathrm{ml} / \mathrm{min}$ and by injecting $2 \mu l$ of ethanethiol to the pulse reactor.

It was ascertained that $\mathrm{SiO}_{2}$ and $\mathrm{KG}$, which have slight acidity, were inactive for the cracking of ethanethiol and that $\mathrm{CaO}^{7}$ and $\mathrm{MgO}^{7}$, which are members of the solid base family, were also inactive. $\mathrm{SA}^{8)}, \mathrm{SPA}^{9)}, \mathrm{Al}_{2} \mathrm{O}_{3}{ }^{10)}, \mathrm{HY}^{11)}$, and $\mathrm{MeY}^{12)}$, which have the acid sites, showed cataly-

Table 1 Catalytic Activities of Various Solid Catalysts for the Cracking of Ethanethiol

Reaction temperature $=400^{\circ} \mathrm{C}$,

Carrier gas flow rate $=30 \mathrm{ml} / \mathrm{min}$,

Volume of reactant pulse $=2 \mu \mathrm{l}$

\begin{tabular}{l|c|c|c|c}
\hline \multicolumn{1}{c|}{ Catalyst } & $\begin{array}{c}\text { a) } \\
\text { Weight } \\
(\mathrm{g})\end{array}$ & $\begin{array}{c}\text { Conversion } \\
(\%)\end{array}$ & $\begin{array}{c}\text { Diethyl- } \\
\text { sulfide } \\
\text { Formation } \\
(\%)\end{array}$ & $\begin{array}{c}\left.k \times 10^{-2} \mathrm{~d}\right) \\
(\mathrm{m} l / \mathrm{g} \cdot \mathrm{min})\end{array}$ \\
\hline $\mathrm{Al}_{2} \mathrm{O}_{3}$ & 0.01 & 58.8 & 26.6 & $\overline{0}$ \\
$\mathrm{SiO}_{2} \cdot \mathrm{Al}_{2} \mathrm{O}_{3}$ & 0.10 & 23.3 & 0 & 1.00 \\
$\mathrm{SPA}^{\mathrm{b})}$ & 0.10 & 43.8 & 0 & 0.54 \\
$\mathrm{HYc}$ & 0.08 & 74.2 & 0 & 56.0 \\
\hline
\end{tabular}

a) Catalysts calcined in the atmosphere at $500^{\circ} \mathrm{C}$ for 3 4 hours.

b) Solid phosphoric acid.

c) $\%$ ion-exchanged $=78.6$.

d) First order rate constant of ethanethiol cracking calculated from Fig. 2. tic activity for the cracking of ethanethiol as shown in Table 1. In this paper, the term "Cracking" was defined by the breaking of C-S bond in ethanethiol molecule to form ethylene and hydrogen sulfide.

Furthermore, the cracking of ethanethiol was carried out with other metallic oxides, metallic sulfides, metallic phosphates and metallic sulfates. In these cases, complex side reactions occurred in addition to the cracking of ethanethiol.

When SA, SPA, HY and MeY were used, the cracking products were only ethylene and hydrogen sulfide. In the case of ethanethiol cracking on $\mathrm{Al}_{2} \mathrm{O}_{3}$, the products were ethylene, hydrogen sulfide and a substantial amount of diethylsulfide. Diethylsulfide was probably formed by the disproportionation of ethanethiol. In any event, the cracking of ethanethiol was enhanced in the presence of solid acid catalysts such as SA, SPA, $\mathrm{Al}_{2} \mathrm{O}_{3}, \mathrm{HY}$ and $\mathrm{MeY}$.

From these results mentioned above, it can be considered that the active sites for the cracking of ethanethiol are the acid sites of the solid acid catalysts. Thus, the detailed studies with respect to the kinetics of the cracking reaction, the types of the effective acid sites of the solid acid catalysts and the reaction mechanisms on these solid acid catalysts will hereinafter be discussed.

\subsection{Kinetic Analysis}

It was reported that the cracking of hydrocarbon such as cumene on the solid acid catalysts can be described by the first order irreversible kinetics $^{13)}$. In the present study, we have attempted to determine whether the cracking of ethanethiol on SA, SPA, and HY can be approximated by the first order kinetics. The value of $W / F$ was, thus, plotted against the value of $-\ln (1-x)$ as shown in Fig. 1, where $W(\mathrm{~g})$ is the weight of catalyst and $F(\mathrm{ml} / \mathrm{min})$ is the flow rate of carrier gas and $x$ is the fractional conversion of ethanethiol. The experiments on the changing of $W \mid F$ were carried out by changing the weight of catalyst and the flow rate of carrier gas was maintained at constant.

It is evident from Fig. 1 that the straight lines passing through the origin were obtained. This indicates that the cracking of ethanethiol can approximately be described by the first order irreversible kinetics. The evaluation of apparent first order rate constants of ethanethiol cracking on SA, SPA and HY were also shown in Table 1. When $\mathrm{Al}_{2} \mathrm{O}_{3}$ was used, the cracking of ethane- 


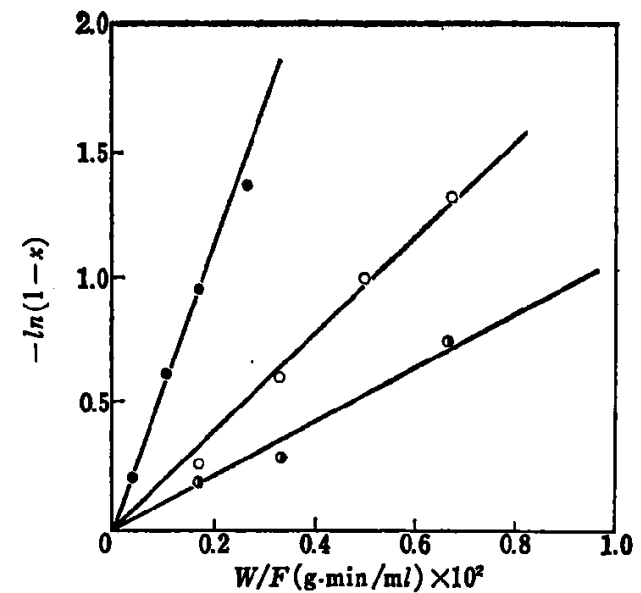

○: HY, O: Solid phosphoric acid, O: $\mathrm{SiO}_{2} \cdot \mathrm{Al}_{2} \mathrm{O}_{2}$

Fig. 1 Relationship between $W / F$ and $-\ln (1-x)$ in the Cracking of Ethanethiol on Various Solid Acid Catalyst at $400^{\circ} \mathrm{C}$

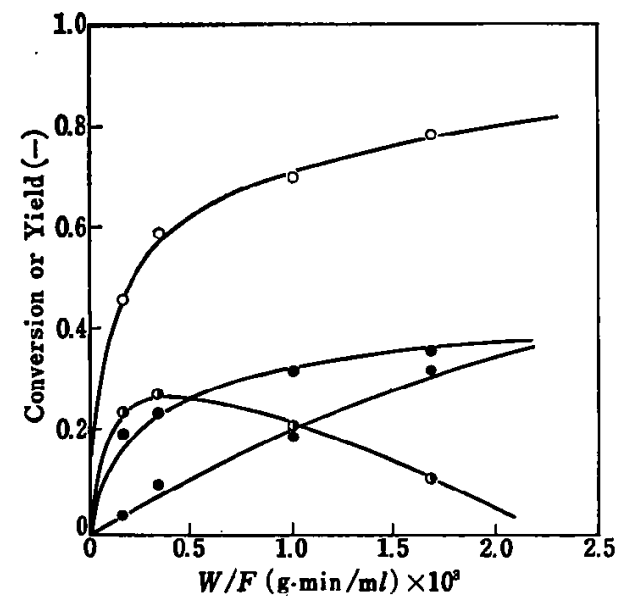

$O:$ Total conversion, $O$ : Ethylene,

○: Hydrogen sulfide, $\boldsymbol{O}$ : Diethylsulfide

Fig. 2 Effect of Contact Time on the Gracking and Disproportionation of Ethanethiol on $\mathrm{Al}_{2} \mathrm{O}_{3}$ at $400^{\circ} \mathrm{C}$

thiol was quite complex. Thus, the kinetics could not be correlated by a simple first order rate equation.

3.3 The Reaction Path of Cracking and Disproportionation of Ethanethiol over $\mathbf{A l}_{2} \mathbf{O}_{3}$

When $\mathrm{Al}_{2} \mathrm{O}_{3}$ was used, a substantial amount of diethylsulfide was also formed in the cracking of ethanethiol as shown in Table 1. For the purpose of clarifying the reaction path of ethanethiol, the conversion of ethanethiol and the yield of ethylene, hydrogen sulfide and diethylsulfide were plotted against the contact time, $W / F$. These plots are shown in Fig. 2.

As can be seen from Fig. 2, the curves of the

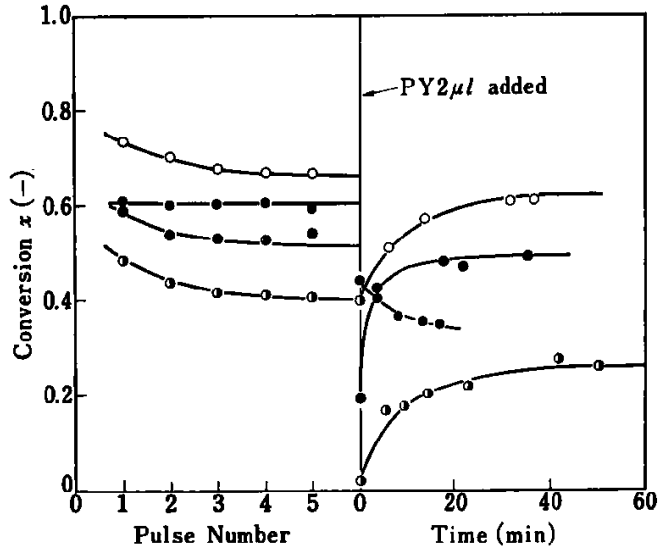

Volume of pyridine pulse $=2 \mu l$

$O$ : Solid phosphoric acid $0.20 \mathrm{~g}$,

: $\mathrm{HY} 0.05 \mathrm{~g}, \odot: \mathrm{Al}_{2} \mathrm{O}_{3} 0.01 \mathrm{~g}$

a: $\mathrm{SiO}_{2} \cdot \mathrm{Al}_{2} \mathrm{O}_{3} 0.20 \mathrm{~g}$

Fig. 3 Effect of the Pyridine (PY) Poisoning on the Cracking of Ethanethiol on the Various Solid Acid Catalysts at $400^{\circ} \mathrm{C}$

relationship between the yield of diethylsulfide and the contact time have a maximum. This implies that diethylsulfide was formed as a product of the disproportionation of ethanethiol and was further decomposed to yield ethylene and hydrogen sulfide. In the initial stage of the reaction, ethylene was also formed. This experimental result suggests that, in the initial stage of the reaction, the cracking (path 1) and the disproportionation (path 2) occurred simultaneously. Consequently, the following reaction path was proposed for the reaction of ethanethiol over $\mathrm{Al}_{2} \mathrm{O}_{3}$.

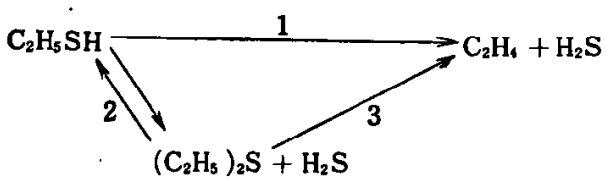

\subsection{Pyridine Poisoning of SA, SPA, $\mathrm{Al}_{2} \mathrm{O}_{3}$ and $\mathbf{H Y}$}

For the purpose of clarifying the effect of the acidity of the solid acid catalysts on the cracking of ethanethiol, the following experiments were performed. When conversion of ethanethiol became constant after several pulses of ethanethiol, $2 \mu l$ of pyridine was injected to the reactor. Figure 3 shows the effect of the pyridine poisoning on the activities of the various solid acid catalysts used in the present investigation.

It can be seen from Fig. 3 that the cracking activities of SA, SPA, $\mathrm{Al}_{2} \mathrm{O}_{3}$ and $\mathrm{HY}$ decreased immediately after the injection of pyridine, 
Table 2 Cracking Reactivities of Aliphatic Thiols on the Silica-Alumina Catalyst in the Temperature Range of $200^{\circ} \mathrm{C}$ to $300^{\circ} \mathrm{C}$

\begin{tabular}{|c|c|c|c|}
\hline \multirow{2}{*}{ Reactants } & \multicolumn{3}{|c|}{$\log k(\mathrm{~m} l / \mathrm{g} \cdot \min )$} \\
\hline & $200^{\circ} \mathrm{C}$ & $250^{\circ} \mathrm{C}$ & $300^{\circ} \mathrm{C}$ \\
\hline $\begin{aligned} \mathrm{C}_{2} \mathrm{H}_{5} \mathrm{SH} & (\mathrm{EM}) \\
n-\mathrm{C}_{3} \mathrm{H}_{7} \mathrm{SH} & (n-\mathrm{PM}) \\
i-\mathrm{C}_{3} \mathrm{H}_{7} \mathrm{SH} & (i-\mathrm{PM}) \\
n-\mathrm{C}_{4} \mathrm{H}_{9} \mathrm{SH} & (n-\mathrm{BM}) \\
s e c-\mathrm{C}_{4} \mathrm{H}_{9} \mathrm{SH} & (s-\mathrm{BM})\end{aligned}$ & $\begin{array}{r}-1.83 \\
-1.71 \\
1.05 \\
-1.43 \\
1.12\end{array}$ & $\begin{array}{r}-0.62 \\
-0.50 \\
1.99 \\
-0.23 \\
2.27\end{array}$ & $\begin{array}{r}-0.38 \\
0.50 \\
2.78 \\
0.82 \\
3.18\end{array}$ \\
\hline
\end{tabular}

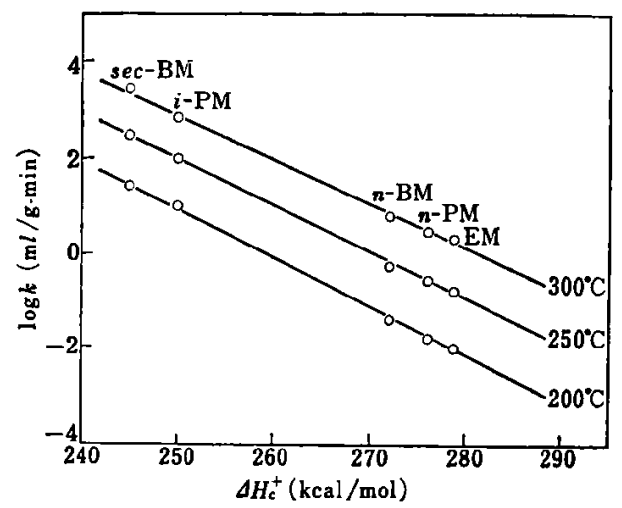

Fig. 4 Relationship between the Logarithms of Apparent Rate Constants in the Cracking of Aliphatic Thiols and the Enthalpy Change, $\mathrm{AHC}^{+}$, in the Reaction of Hydride Abstraction from the Corresponding Paraffins

These experimental results suggest that these solid acid catalysts such as $\mathrm{SA}, \mathrm{SPA}, \mathrm{Al}_{2} \mathrm{O}_{3}$ and $\mathrm{HY}$ contributed greatly to the cracking of ethanethiol.

\subsection{Cracking Reactivities of Various Ali- phatic Thiols on SA}

For the purpose of clarifying the cracking mechanism of ethanethiol on SA, the cracking reactivities of various aliphatic thiols on $\mathrm{SA}$ were studied. The cracking reactivities of various aliphatic thiols at the reaction temperatures ranging from $200^{\circ} \mathrm{C}$ to $300^{\circ} \mathrm{C}$ are listed in Table 2. In the present report, the cracking reactivity will be expressed in the term of logarithms of an apparent first order rate constant.

As is evident in Table 2, the cracking reactivities of various aliphatic thiols from $200^{\circ} \mathrm{C}$ to $300^{\circ} \mathrm{C}$ increased in the following order ${ }^{14}$;

$\mathrm{C}_{2} \mathrm{H}_{5} \mathrm{SH}<n-\mathrm{C}_{3} \mathrm{H}_{7} \mathrm{CH}<n-\mathrm{C}_{4} \mathrm{H}_{9} \mathrm{CH}<i-\mathrm{C}_{3} \mathrm{H}_{7} \mathrm{SH}<$ sec $-\mathrm{C}_{4} \mathrm{H}_{9} \mathrm{SH}$.

This order is also consistent with the order to the stability of alkyl carbonium ions produced from the corresponding alkyl groups. A liner relationship was observed between the logarithms

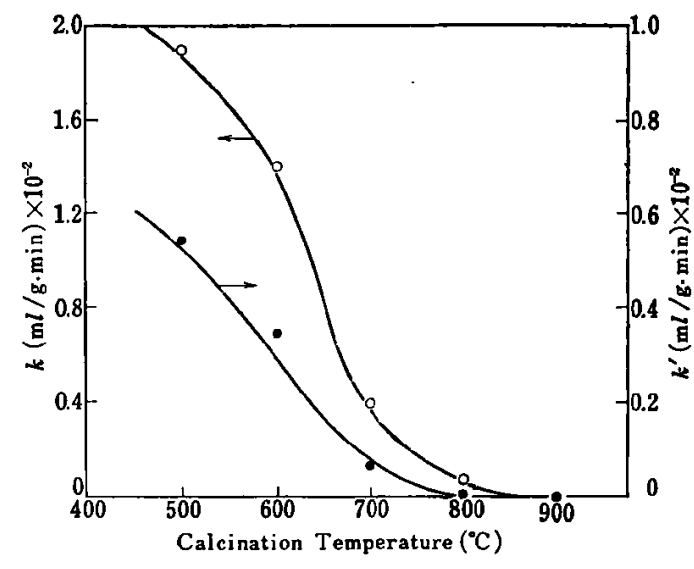

O: Ethanethiol, $O$ : Cumene

Fig. 5 Changes of Activities of Solid Phosphoric Acid for the Cracking of Ethanethiol and Cumene by the Calcination Temperature

of the apparent first order rate constant in the cracking of aliphatic thiols and the enthalpy change, $\Delta \mathrm{Hc}^{+}$, in the formation of carbonium ion from the corresponding paraffins as shown in Fig. 4.

From these results, it was proposed that the catalytic cracking of aliphatic thiols on SA takes place with the carbonium ion mechanism which is related to the proton of SA.

3.6 Relationship between the Activities and the Calcination Temperature of SPA and $\mathrm{HY}$

In order to obtain more definite knowledge as to the nature of the active sites of SPA and HY, the following experiments were performed.

It has been reported that the acidity of SPA ${ }^{15}$ ) and $\mathrm{HY}^{11)}$ depends considerably upon the calcination temperature. Thus, we studied the effect of the calcination temperature on the activities of SPA and HY for the cracking of ethanethiol and cumene at $400^{\circ} \mathrm{C}$. The results are shown in Fig. 5 and 6.

It can be seen from Fig. 5 and 6 that the activities of SPA and HY for the cracking of ethanethiol and cumene decreased with the increase of the calcination temperature.

In Fig. 6, we also show the results of J. W. Ward ${ }^{11)}$ by the dotted lines. By the infrared spectroscopy of catalysts treated with pyridine, Ward determined the ratio of concentration of the Brönsted acid sites to that of the Lewis acid sites of the zeolites which were ion exchanged with $\mathrm{NH}_{4}{ }^{+}$and calcined at various temperatures ${ }^{11)}$. The changes of the activities of HY in the cracking of ethanethiol and cumene by the calcination

Bulletin of The Japan Petroleum Institute 


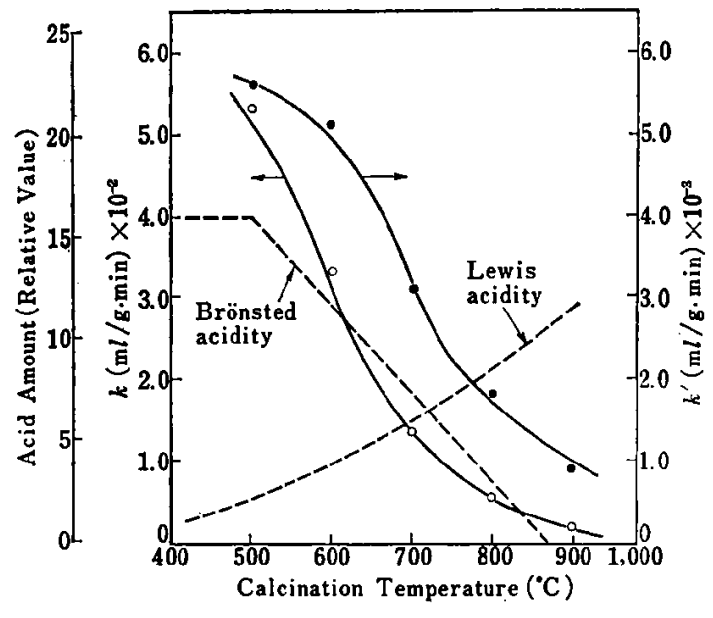

O: Ethenethiol, O: Cumene

The dotted lines are the experimental results of Ward 11)

Fig. 6 Changes of Activities of HY-Zeolite for the Cracking of Ethanethiol and Cumene by the Calcination Temperature

agreed well with the decrease in the Brönsted acidity determined by Ward but was independent on that of Lewis acidity as shown in Fig. 6.

It is evident from these results that the Brönsted acid sites of SPA and HY provided the active sites for the cracking of ethanethiol as well as SA.

\subsection{Effect of the Metal Ion on the Cracking of Ethanethiol over MeY}

Examination of Table 1 showed that HY was active for the cracking of ethanethiol. Thus, we also studied the activities of various $\mathrm{MeY}$, which were ion-exchanged with alkali metal ions, alkali earth metal ions and transition metal ions etc. for the cracking of ethanethiol. Various kinds of MeY, percentage of ion-exchanged, electronegativity of metal ion in $\mathrm{MeY}$ and the apparent first order rate constant in the cracking of ethanethiol at the first pulse are shown in Table 3. The electronegativity of metal ion is that obtained by $\mathbf{K}$. Tanaka, et al. ${ }^{16)}$.

It was found that the order of the activity of $\mathrm{MeY}$ in the cracking of ethanethiol was as follows:

\section{$\mathrm{NiY}>\mathrm{CoY}>\mathrm{ZnY}>\mathrm{CdY}>\mathrm{CuY}>\mathrm{AgY}>\mathrm{PbY}>$} $\mathrm{MnY}>\mathrm{AlY}>\mathrm{BaY}>\mathrm{CaY}>\mathrm{MgY}>\mathrm{NaY}>\mathrm{FeY}$.

This order was not in accord with that of the cumene cracking at $400^{\circ} \mathrm{C}$ as shown in Table 3. On the other hand, the catalytic cracking of ethanethiol on $\mathrm{MeY}$ except $\mathrm{NaY}$ was poisoned by pyridine $^{17)}$. Due to the poisoning, the activity of $\mathrm{MeY}$ decreased with increasing electronegativity $\chi_{i}$ of metal ions in the catalysts ${ }^{17}$. Further.
Table 3 Catalytic Activities of Metal-Ion Exchanged Y Zeolite Catalysts at $400^{\circ} \mathrm{C}$

\begin{tabular}{|c|c|c|c|c|}
\hline \multirow{2}{*}{ Catalysts } & \multirow{2}{*}{$\begin{array}{c}\% \text { Ion- } \\
\text { Exchanged }\end{array}$} & \multirow{2}{*}{$\begin{array}{c}\text { Electro- } \\
\text { negativity } \\
\chi_{i}\end{array}$} & \multicolumn{2}{|c|}{$\begin{array}{c}\text { Activity } k \\
(\mathrm{~m} l / \mathrm{g} \cdot \mathrm{min}) \times 10^{-2}\end{array}$} \\
\hline & & & $k_{1}{ }^{b)}$ & $k_{e}{ }^{c)}$ \\
\hline $\begin{array}{l}\mathrm{NiY} \\
\mathrm{CoY} \\
\mathrm{ZnY} \\
\mathrm{CdY} \\
\mathrm{CuY} \\
\mathrm{AgY} \\
\mathrm{PbY} \\
\mathrm{MnY} \\
\mathrm{AlY} \\
\mathrm{BaY} \\
\mathrm{CrY} \\
\mathrm{CaY} \\
\mathrm{MgY} \\
\mathrm{NaY} \\
\mathrm{FeY}\end{array}$ & $\begin{array}{r}68.8 \\
71.4 \\
78.6 \\
75.2 \\
77.3 \\
93.9 \\
90.6 \\
69.3 \\
82.1 \\
79.5 \\
98.3 \\
73.8 \\
69.2 \\
92.9\end{array}$ & $\begin{array}{r}9.0 \\
9.0 \\
8.0 \\
8.5 \\
9.5 \\
5.7 \\
9.0 \\
7.5 \\
10.5 \\
4.5 \\
11.2 \\
5.0 \\
6.0 \\
2.7 \\
12.6\end{array}$ & $\begin{array}{r}93.0 \\
70.6 \\
42.6 \\
32.3 \\
32.2 \\
18.4 \\
22.8 \\
13.4 \\
8.0 \\
7.0 \\
5.2 \\
4.1 \\
3.2 \\
1.9 \\
0.9\end{array}$ & $\begin{array}{r}55.9 \\
72.7 \\
101.0 \\
18.5 \\
45.7 \\
46.3 \\
0 \\
28.1 \\
3.3 \\
0 \\
0.6 \\
20.4 \\
31.2 \\
0 \\
0\end{array}$ \\
\hline
\end{tabular}

a) $\mathrm{Fe}^{3+}$

b) Initial activity in the cracking of ethanethiol.

c) Initial activity in the cracking of cumene.

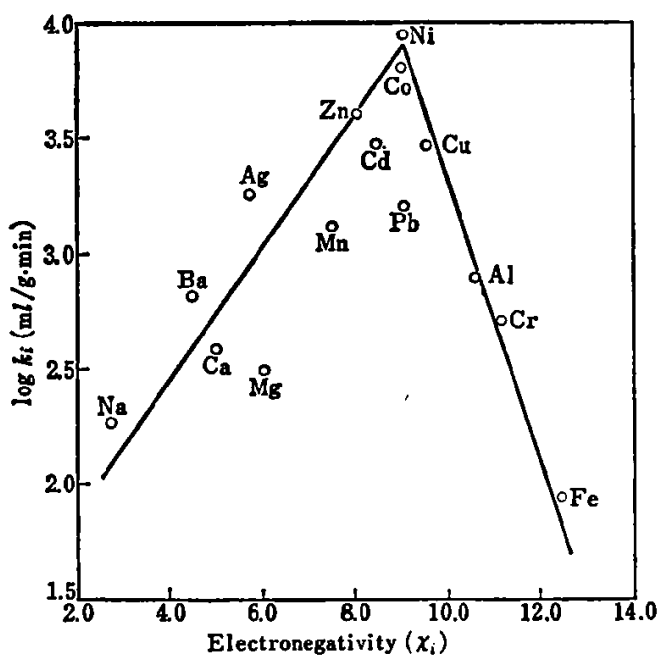

Fig. 7 Relationship between the Electronegativity $\chi_{i}$ of Metal Ions and the Logarithms of the Initial Activity of Metal-Ion Exchanged $Y$ Zeolite Catalysts in the Cracking of Ethanethiol at $400^{\circ} \mathrm{C}$

more, a volcano shape order was observed between the catalytic activity for the ethanethiol cracking and the electronegativity $\chi_{i}$ of metal ion in the catalysts as shown in Fig. 7.

Based on these results, it was suggested that the active sites of $\mathrm{MeY}$ for the cracking of ethanethiol are mainly the metal ions.

\subsection{Gracking Mechanism of Ethanethiol on the Individual Solid Acid Catalysts}

Table 1 shows that SA, SPA and HY which possess the Brönsted acid sites ${ }^{8), 9)}$ were active for the cracking of ethanethiol.

Table 1 also shows that $\mathrm{Al}_{2} \mathrm{O}_{3}$, which has mainly both Lewis acid sites and basic sites ${ }^{10)}$, accele: ated the cracking and disproportionation 
of ethanethiol.

The results of the present study indicate that the types of effective active site of the catalysts and the cracking mechanism of ethanethiol are different when the types of solid acid catalysts used in the experiment are different. Accordingly, the effective active site of the individual solid acid catalysts and the cracking mechanism of ethanethiol were considered.

Regarding the active sites of SA, SPA and HY, as discussed in Section 3.5 and 3.6, the active sites are the Brönsted acid sites. Thus, the cracking of ethanethiol proceeds according to the following carbonium ion mechanism.

$$
\begin{array}{ll}
\mathrm{C}_{2} \mathrm{H}_{5} \mathrm{SH}+\mathrm{H}^{+} \rightleftharpoons \mathrm{C}_{2} \mathrm{H}_{5} \stackrel{+}{\mathrm{S}} \mathrm{H}_{2} \\
\mathrm{C}_{2} \mathrm{H}_{5} \stackrel{+}{\mathrm{S}} \mathrm{H}_{2} \longrightarrow \mathrm{C}_{2} \mathrm{H}_{5}++\mathrm{H}_{2} \mathrm{~S} \\
\mathrm{C}_{2} \mathrm{H}_{5}{ }^{+} & \rightleftharpoons \mathrm{C}_{2} \mathrm{H}_{4}+\mathrm{H}^{+}
\end{array}
$$

Next, we shall discuss the active sites of $\mathrm{Al}_{2} \mathrm{O}_{3}$ and reaction mechanism. As shown in Fig. 3, $\mathrm{Al}_{2} \mathrm{O}_{3}$ was poisoned by pyridine. This indicates that the acid sites (Lewis acid sites) of $\mathrm{Al}_{2} \mathrm{O}_{3}$ contributed to the cracking and disproportionation of ethanethiol. On the other hand, solid bases such as $\mathrm{CaO}$ and $\mathrm{MgO}$ were inactive for the cracking of ethanethiol as described in Section 3.1. This indicates that the cracking and disproportionation of ethanethiol did not occur on the basic site alone of $\mathrm{Al}_{2} \mathrm{O}_{3}$.

Furthermore, the activity changes of $\mathrm{HY}$ calcined at various temperatures correlated well with the changes in the amount of the Brönsted acidity but were independent of the amount of Lewis acidity as shown in Fig. 6.

As described before, it has been reported that $\mathrm{Al}_{2} \mathrm{O}_{3}$ has both Lewis acid sites and basic sites ${ }^{10}$ ).

On the basis of the above discussions, it was postulated that the cracking and disproportionation of ethanethiol with $\mathrm{Al}_{2} \mathrm{O}_{3}$ takes place according to the following mechanism in which the Lewis acid sites and the basic sites are jointly involved in the cracking and disproportionation of ethanethiol.

First, the cracking reaction of ethanethiol proceeds via Eq. (5)

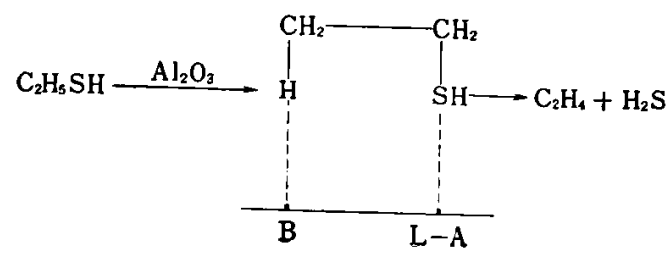

Where L-A and B denote the Lewis acid sites and the basic sites, respectively. Furthermore, diethylsulfide formation was also observed by the disproportionation of ethanethiol. To form diethylsulfide from ethanethiol, the rupture of the $\mathrm{C}-\mathrm{S}$ bond and the $\mathrm{S}-\mathrm{H}$ bond of the ethanethiol molecule must occur. It was, thus, postulated that the rupture of the $\mathrm{C}-\mathrm{S}$ bond takes place on the Lewis acid sites and that of the $\mathrm{S}-\mathrm{H}$ bond occurs on the basic sites.

On the basis of this postulated mechanism, diethylsulfide may be formed from ethanethiol according to the steps given by Eq. (6), (7), (8) and (9).
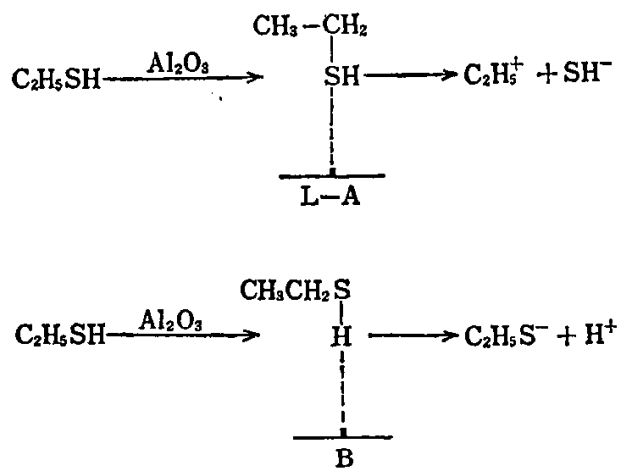

$$
\begin{aligned}
& \mathrm{C}_{2} \mathrm{H}_{5}++\mathrm{C}_{2} \mathrm{H}_{5} \mathrm{~S}-\longrightarrow \mathrm{C}_{2} \mathrm{H}_{5} \mathrm{SC}_{2} \mathrm{H}_{5} \\
& \mathrm{H}^{+}+\mathrm{SH}^{-} \longrightarrow \mathrm{H}_{2} \mathrm{~S}
\end{aligned}
$$

Finally, we shall discuss the active sites of $\mathrm{MeY}$ which are effective for the cracking of ethanethiol. Based on the results shown in Section 3.7, it was suggested that the active sites of $\mathrm{MeY}$ for the cracking of ethanethiol are mainly the metal ions. Thus, it is assumed that the cracking mechanism of ethanethiol is as follows.

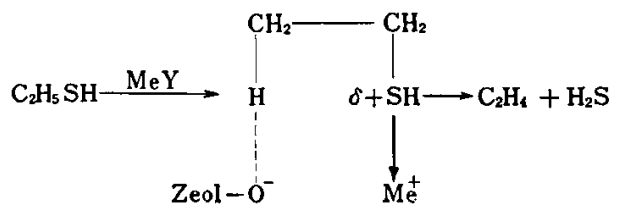

where $\mathrm{Zeol}-\mathrm{O}^{-} \mathrm{Me}^{+}$, $\mathrm{Zeol}-\mathrm{O}^{-}$and $\mathrm{Me}^{+}$are the $\mathrm{MeY}$, skeletal structure of zeolite and metal ion, respectively.

In this cracking mechanism, we assumed that the ethanethiol molecule will be strongly absorbed onto the metal ion at the sulfur atom and weakly onto the skeletal structure oxygen to form the reaction intermediate.

If the metal ion in $\mathrm{MeY}$ is the sole active site for the cracking of ethanethiol, the cracking of ethanethiol would proceed with only the Lewis acid sites. This contradicts with the results of 
cracking over HY in which ethanethiol was not cracked by only the Lewis acid sites, since the metal ion in MeY is the Lewis acid sites.

And a volcano shape order of the catalytic activity against the electronegativity $\chi_{i}$ of metal ion was observed as shown in Fig. 7. In the catalytic reactions, it has often been observed the volcano shape order of the catalytic activity against the electronegativity of metal ion in the catalysts or against the heat of formation of reaction intermediate ${ }^{18) ~ 21)}$. There are two main explanations with respect to the cause of the volcano shape order of the catalytic activity. The one explanation is that the cause of the volcano shape order of the catalytic activity is attributed to the change of reaction mechanism on the borders of the catalysts located at the top of the volcano shape ${ }^{17)}$.

Another explanation is the change of the rate determining step on that catalysts2)

In the present study, it was observed that the cracking products of ethanethiol on each $\mathrm{MeY}$ were identical. And it was assumed that the active sites of each $\mathrm{MeY}$ for the cracking of ethanethiol is mainly the metal ions in the catalyst.

By these reasons, we concluded that the cause of the volcano shape order of the catalytic activity against the metal ion in the catalyst as observed in Fig. 7 is attributed to the change of the rate determining step in the cracking of ethanethiol on the border of the catalysts located at the top of the volcano shape ${ }^{17}$.

\section{Conclusions}

Solid acid catalysts such as SA, SPA, $\mathrm{Al}_{2} \mathrm{O}_{3}$, $\mathrm{HY}$ and $\mathrm{MeY}$ showed the activity for the cracking of ethanethiol but the solid bases such as $\mathrm{CaO}$ and $\mathrm{MgO}$ were inactive. Therefore, the acid sites of these solid acid catalysts accelerate the cracking of ethanethiol. However, the type of effective acid sites of these solid acid catalysts for the cracking of ethanethiol were different. It was, thus, concluded that the active sites of SA, SPA and HY were the Brönsted acid sites, and that the active sites of $\mathrm{Al}_{2} \mathrm{O}_{3}$ were both Lewis acid sites and basic sites, and that the active sites of MeY were mainly the metal ions.

And the reaction mechanisms were proposed for the cracking of ethanethiol over the individual solid acid catalysts.

\section{References}

1) Kieran, P., Kemball, C., J. Catalysis, 4, 380 (1965).

2) Sterfield, C. N., Robert, G. W., A. I. Ch. E. Joumal., 14, 159 (1968).

3) Kolboe, S., Amberg, C. H., Can. J. Chem., 47, 352 (1.969).

4) Lipsch, J. M. J. G., Schuit, G. C. A., J. Catalysis, 15, 163 (1969).

5) Smith, G. V., Hinckley, G. G., ibid., 30, 218 (1973).

6) Sugioka, M., Hirano, T., Yotsuyanagi, T., Aomura, K., J. Chem. Soc. Japan (Ind. Chem. Sect.), 73, 2176 (1970).

7) Tanabe, K., "Solid Acids and Bases", 2 (1970) Kodansha, Tokyo and Academic Press, New York, London.

8) ibid., p. 58.

9) ibid., p. 94 .

10) ibid., p. 48.

11) Ward, J. W., J. Catalysis, 9, 225 (1967).

12) Ward, J. W., ibid., 22, 237 (1971).

13) Echigoya, E., Ochiai, Y., J. Chem. Sec. Japan (Ind. Chem. Sect.), 69, 1858 (1966).

14) Sugioka, M., Aomura, K., Bull. Japan Petrol. Inst., 15, (2), 136 (1973).

15) Mitsutani, A., Hamamoto, Y., J. Chem. Soc. Japan (Ind. Chem. Sect.), 67, 1231 (1964).

16) Tanaka, K., Ozaki, A., Tamaru, K., Shokubai, 6, 262 (1964).

17) Sugioka, M., Aomura, K., J. Chem. Soc. Japan, 1973, 1281.

18) Mochida, I., Yamamoto, H., Anju, Y., Kato, A. Seiyama, T., Shokubai, 13, 31 (1971).

19) Kominami, N., Kawarazaki, K., Yamazaki, Y., Sakurai, N., ibid., 7, 359, 363 (1965).

20), Fahrenhort, J., Van Reyen, L. L., Sachtler, W. H. H., "The Mechanism of Heterogeneous Catalysis", 23 (1960) Amsterdam.

21) Shiba, T., Kèi, T., Ozaki, A., "Shokubai Gairon", 98 (1972) Kyoritsu Toshyo. 